rise to the mental conflict, a process which involves not only a general understanding of the mental processes involved, but a capacity on the part of the physician of seeing himself in the situation that the patient describes in order that he may understand what the particular elements are which make the appearance of the conversion symptom necessary. The patient will hide the cause even if he is aware of it. He will discuss his whole life for an hour and, perhaps, give you a hint of the real trouble just before the end of the interview. It is often these hints which are of the greatest value to the psychologist. They may be mentioned quite casually or they may be associated with restless movements and uneasiness in the patient's demeanour or they may be accompanied by an outburst of weeping. It is my practice to follow these indications quietly and, if necessary, to prolong the interview so as to take full advantage of the communicative state to which the patient has arrived. Once the patient feels that the attitude of the physician is sympathetic, no difficulty will be experienced at subsequent interviews in obtaining a full account of the whole condition.

The patient is usually well aware of the disturbance of mind from which he has suffered or is suffering and recognises that the conditions are causing unhappiness or dread or some other painful emotion, but such is the nature of these cases, that he does not associate cause and symptom and will often resist the idea. In practice this makes no difference to treatment.

Any difficult conditions in the patient's life must be investigated and brought fully into the patient's consciousness. They must then be dealt with either by the removal of the condition, if that is possible, or by a conscious acquiescence and a correct mental adjustment to the difficulty. The symptom should be retained until this process is complete. It is of value as an indicator to show whether or not the work has been completed. Sometimes, when the patient's mind is at rest, the symptom will disappear spontaneously, but it most frequently happens, as has been previously mentioned, that something more is needed to remove the symptom, and if the method can be made rather dramatic it helps the patient to give up a symptom and at the same time to retain his self regard. He is bound to feel rather a fool if he is cured by cold logical common sense. Full advantage is taken of this by the practitioners of the unqualified type in treating these patients and, because of the failure of ordinary medicine to deal correctly with these conditions, these cases tend to fall into the hands of those practitioners who have been taught along less orthodox lines. It should never happen that the regular practitioners of medicine fail to cure them.

Suggestion, with or without hypnosis, electrical treatments, sudden shock, or any similar method will serve to remove the symptom, but the real work of cure is effected when the psychological investigation, the explanation of the condition, and the re-education of the patient are complete.

\section{NOTES ON POST-GRADUATE WORK IN VIENNA.}

\author{
RY
}

J. L. MEAGHER, M.D., B.S. MeLb., L.M. Coombe.

These notes on post-graduate opportunities are mainly personal impressions, and are the result of experience during six months' study in Vienna. Three main facts emerge :-

1. The effectiveness of the teaching organisation and the excellence of the teaching.

2 . The great range and quantity of the clinical material and its availability for the purposes of the post-graduate student.

3. The cordial spirit of the teachers toward the post-graduates and the disinterestedness of the teachers.

The University.

These, apart from the romance inseparable from the city and the medical side of its artistic life, are the chief impressions. The success of post-graduate teaching in Vienna is a consequence of and a tribute to the excellent organisation of the University authorities, for it continues in spite of the absence of elementary provision for the comfort of the large body of post-graduates in the city. Their numbers are difficult to estimate. They include few Englishmen, some from the Dominions, manyo Americans, Continentals from every quarter, and men from South America, Egypt, and Asia. The majority. appear to be American, but a great many students not from English-speaking countries are scattered in various parts of the city. The number of women post-graduates from the English-speaking countries is small. The American Medical Association provides the only club purely for medical post-graduates. As a club it was, in 1924, in the common opinion of members, very much less than satisfactory. But in spite of this handicap in social life-Vienna at the time, be it remembered, was a desperately poor city-the universal feeling of the post-graduates respecting the work in the medical schools which they were able to do, was of enthusiastic appreciation.

The post-graduate teaching in Vienna so far as regards the majority of English-speaking students there to-day is the outcome of an arrangement between the American Medical Association and the Medical Faculty. The Association is a very successful body, possessing a surplus of funds, founded some 30 years ago for the organisation of medical post-graduate work, and the promotion of the social side of life among its members.

The conditions of post-graduate study are laid down by the Faculty.

Teachers and Courses.

Part of the duties of the professors in the various branches of medicine is to teach in the hospitals. OO 
Some live inside the hospital, others near it. They must make the teaching available to the postgraduates. A proportion of their income is derived from post-graduate fees. They have the privilege, in addition, of private practice. Both were welcome supplementary sources of income, since at this time of depression the salaries of all public officials were inadequate. The fees which they may charge are fixed; they are based upon a rate per hour, and vary according to the standing of the teacher. The highest regularly-charged fee authorised by the University in 1924 was 10 dollars per hour. One or two men only were in receipt of it. The rate was expressed in dollars because the Americans were the chief bidders for these services. Men of lesser learning were entitled to charge 7 dollars, but only in a few cases. Assistants could charge no more than 5 dollars. Some charged only 3 dollars.

The professors did teach. Those whose duties were entirely academic-as, for instance, a lecturer in physiology - were very glad to do so. Usually the rate.was higher for the clinical teachers; in rare instances there was over-payment, or what might have been regarded as such by some, for services rendered. Whether the teacher was engaged by a group of three, five, or more students or by an individual, was a matter of circumstances. All ranks among the medical men attached to the hospital, from the professors to assistants, possessed the right, and in the great majority of cases the ability, to teach. The attendants took a hand in it. It was open to an assistant in any department to advertise upon the hospital notice-board a course in his speciality, to charge the recognised rate per hour for his services, and to conduct a course within the hospital in his own time, using the hospital material. Some of these courses were practical, others theoretical. If they were lectures, they might be given in German only. Some were limited to Germans and Austrians, others were intended as well for "Auslanders "- the nationals of foreign or of recently enemy countries. Some of these courses did not become popular ; some, such as the practice of intubation upon anæsthetised dogs, developed into a continually-repeated demonstration attended chiefly by "Auslanders." Most became permanent institutions, after a time well recognised among the attractions in the speciality in question. Many were given intermittently as opportunity offered, to groups of men interested, at the request of some post-graduate student better acquainted than his fellows with the disposition and ability of particular teachers. Thus, some of the most interesting and most valuable courses were arranged entirely through the initiative of the post-graduates, by private arrangement with men who had almost, if not completely, abandoned teaching but were willing to hold a class, and considered it an honour to be called upon in this way.

The part the University played was to license the services of the teachers and to provide by a formal process of matriculation for the attendance of post-graduates at the medical course lectures.

The interest taken in and importance attached to the work of post-graduates on the part of the University was manifested by the issue of a "Zeugnis," an official certificate, to those who had completed a period of three months' work. (Certificates of work done were given also by the respective hospital chiefs.) The University Zeugnis contained the signatures of the various teachers, and bore the University seal. It was much prized by the American students, and its issue was the result of arrangement between the American Medical Association and the Faculty of Medicine.

\section{The Teaching Tradition.}

The most remarkable and lasting impression was the teaching tradition. It manifested itself on the part of the leaders of medicine in a readiness. of access, a willingness, and an undoubted ability to teach. Most of them, and all of the assistants, worked long hours. The teachers spoke with evident delight; some with magnetic enthusiasm ; some, in the presence of a stimulating and numerous audience of post-graduates, with galvanic force. One man of eminence gave on three afternoons a week a demonstration of five hours, unbroken except for perhaps twenty minutes. Younger men made the work a convivial delight. It was an art, a joy, and, as well, a social occasion. It was too, an honour. Some serious-minded men showedin their manner an appreciation of it as a privilege. Post-graduate teaching was an inevitable consequence of the conditions of work of the assistants. It was in harmony with the bent of the professors and hospital staffs. It was powerfully aided by hospital tradition, and the widespread tradition within the ranks of the medical profession and in the minds of the people, even the common people of the city.

Everyone, in the neighbourhood of the Krankenhaus at least, and all the cultured people in Vienna, knew the names and the claim to fame of the professors of medicine and many assistants. The streets are named with names famous in medicine. Public approbation was given to the achievements of the professors as generously and as intelligently as to those of the popular opera singers or artists. Medical fads became public fanaticisms.

In this tradition the post-graduate was a necessary figure. The teaching was largely for his benefit. He could not escape being its propagandist. He was necessarily grateful as being by his years and experience its chief beneficiary.

In the clinics he was received as a colleague and treated as a guest worthy of honour. He was invited to the homes of his teachers. He was treated with deference by the nursing staffs. His right to practise in the wards, if he had enrolled as a voluntary assistant in a hospital, was unquestioned. Every facility was given him to examine patients at the bed-side and to do laboratory work if he chose. 
The Element of Research.

A fact greatly helping medical work, including that of the post-graduate, is the importance attached to research. Such effort is expected of every member of the hospital medical staff. Competition between the various hospitals and their directors and the keen desire on the part of members of the medical profession to become known in the domain of their special work aids this.

Each assistant is allotted, if he does not choose, some investigation to carry out, independently, or in collaboration with a senior. The results are noted in the Wiener Wochenschrift, the leading medical weekly journal of clinical research. Reprints are published independently through a special fund. Post-graduates are stimulated to similar effort and are given access to case-records and made free of the wards. They are in constant, perhaps daily, contact with the head of the department and receive generous encouragement from him and valuable assistance if they chooss to seek it.

The more ambitious post-graduate students do research. Many Americans stay six months, some a year, for the purpose. Some wander from Berlin to Vienna, to Frankfort, and back again to Vienna, and become ardent propagandists of the benefits of studying in the German-speaking centres. They become, by a knowledge of the language and custom of the country, qualified to take advantage of the University curriculum, and having matriculated are enabled to embrace in their activities the whole field of German medical science. Their numbers are few.

The stimulus given by research was clearly shown in the clinical meetings. In the department of children's diseases these were held at 6 o'clock in the evening in the von Pirquet Clinic. They might be attended by 100 , including the heads and many of the assistants from the chief children's hospitals. Seven or eight special subjects might be announced The principal speakers were limited to five minutes, or at the most ten. Their demonstrations were followed by a discussion, a feature of which was the free expression of opinion on the part of men little known. The view of each speaker was received with tolerance. Postgraduates attended in large numbers, and their contribution to the discussion would be welcomed.

In addition to the private courses and those arranged through the American Medical Association, there are given at intervals of three months intensive courses in various specialities-general medicine, children's diseases, oto-laryngology, surgery. In these the most eminent men attached to other branches of medical learning took part, contributing each his quota to the stock-pot of instruction. They consist of lectures and demonstrations, the lectures given in the German tongue. They correspond in character closely with the intensive courses arranged through the Fellowship of Medicine in London. They last ten days or a fortnight.
Fees.

All the fees are arranged by the University, following State policy, with a bias against the Auslander. There are three scales, the lowest for the inhabitants of the German-speaking countries, or of its late Allies, the equivalent of $6 s$. $8 d$. for an intensive course ; a second, perhaps double, applying to nationals of neutrals; and a third, three times as great as that for the Germans, applying to the late enemy Auslanders.

The teachers keep their agreements faithfully. They are punctual and give full value. The teaching is frankly on a commercial basis, but the bargain is fair, even generous in most cases, from the post-graduate point of view. The post graduates are well satisfied, indeed happy, to pay the price. Every class of instruction, in every branch of medicine, theoretical or practical, may be obtained in Vienna-every class, except major operations upon the living subject. Even this could be done by the post-graduate, I was told, after a period of probation in Budapest or Prague, and men went from Vienna to those centres to learn practical surgery. Teaching, either private or public, went on all day long in the hospitals. Thus, if one were enrolled as hospitant, or otherwise by invitation, it would be possible to attend a university lecture-demonstration on children's diseases in the von Pirquet Clinic at 9, a ward demonstration in the same building ato 10.30 , a private lecture at 11 , an invitation demonstration open to all post-graduates, by a⿳亠丷厂 world-famous teacher in a neighbouring clinic at 12, and be occupied profitably during the afternoon and in the evening until 9 o'clock. A man could work on Sundays if he liked. Some did.

Racial antagonism, if it existed, was not manifest. The contrary appeared. Graduates from the Dominions were very cordially received. In proportion to the distance they had travelled seemed the cordiality of the welcome. In the von Pirquet Clinic especially, as I, from Australia, experienced it, warmth of welcome and kindness, largely due to the magnetism of the "Chief," were the universal spirit, and made an unforgettable impression.

The assistants, in most cases, were very hard worked and poorly paid. The pay of a well-known radiologist attached to a large clinic was $£ 100$ per annum or less. He was required to act as house surgeon at night. His hours of leave were few. Some of the assistants, men of mature years, confessed that they could not afford to marry while depending on their salaries. The majority were between 30 and 40 years of age, occupying positions analogous with those of house physician and house surgeon in England. The life and work suited them. They did not wish the life of a physician in practice. The necessity and the desire to teach led to a keenness to acquire a knowledge of English and other languages. Almost all the assistants could speak English. They acquired the knowledge in their spare time and polished it by university courses or conversation classes. 
The language is not a real difficulty for a postgraduate determined for a little effort and intending to stay, say, longer than a month. Even in the case of a man who arrives ignorant completely of German, it is not more than an obstacle. Its main effect may be removed by a little friendly help from his fellow-students and well-disposed teachers. In some specialities, as, for example, oto-laryngology, it is scarcely a bar, for the teaching is almost exclusively given in English. The use of familiar medical Latin terms makes the task of learning from a German clinical lecturer easier. Thus, one man lecturing on post-mortem specimens has evolved a simple vocabulary, which, aided by clear enunciation, gestures, and pointed repetition of difficult words, makes his meaning sufficiently plain. There are not many good teachers in English, of the German language, in Vienna. All postgraduates who intend to visit Vienna should learn as much of the language as they can before they go.

Among outstanding impressions is the comradeship of distinguished men. Many of these leaders mingle with boyish delight with the members of post-graduate classes. The demonstrations are a large and important part of their activities, and, it seems, a considerable recreation. Some men begin at 7 o'clock in the morning giving private lessons.

\section{The Patients.}

The patients in the wards and out-patients' departments of many hospitals, a vast number, form the subjects for the demonstrations. The attendance of the patients for the most part, within a limited radius, and the variety of unusual and striking afflictions, the result of the war, contributed at the time of my visit to Vienna to the excellence of the clinical opportunities. The patients were dragooned for the purposes of the clinic, not by force, but by rule. They took their situation philosophically, mostly in good part. Sometimes they showed resentment at what they considered undue handling. They were, indeed, subjected to much more prolonged examination than is customary in an English hospital, yet the assistants were not lacking in consideration for them and would stop examinations when in their opinion they had lasted long enough. But the feelings of the patients seemed at times to be matters of secondary consideration, and this, to a stranger, was the unattractive aspect of post-graduate work in Vienna. (To be concluded.)

The following Discussions will be held at the Post-Graduate Hostel, Imperial Hotel, Russellsquare, W.C., at 9 P.M.:-

Dec. 1.. Dr. R. M. CAssidy : Precordial Pain.

$" \quad$.. Mr. A. Clifford Morson: Pecant Prostate.

", 9.. Sir Charters Symonds: Carcinoma of the Esophagus.

"10.. Dr. Arnold Chaplin: Medical Service at Sea in the Mercantile Marine.

"14.. Prof. Lovate Evans: Capillary Circulation.

" 16. . Mr. A. E. Mortimer Woolf : Pain.

" 17.. Dr. T. Wilson Parry : The Differential Diagnosis of the Various Kinds of Holes discovered in the Skulls of Prehistoric Man.

\section{EDITORIAL NOTES}

\section{SPECIAL COURSES.}

THe following points concerning the courses arranged for January appear to call for emphasis. Beginning on Jan. 10th, there will be a two weeks' intensive course in cardiology, undertaken by members of the staff at the National Hospital for Diseases of the Heart. The morning sessions will begin at 10 A.M. and last to 12.30 P.M., and the afternoon from 2 to 4 P.M. The entry has been raised to 20 , but in view of the popularity of this course, it is highly desirable that early application for enrolment should be made in order to avoid disappointment.

The Royal Free Hospital and the Children's Clinic will hold for the first time a combined course in diseases of children from Jan. 10th to 22nd. There will be full afternoon session and some morning work. It is intended that all aspects of diseases of children shall be dealt with, so that the course should prove an attractive one.

For those interested in psychological medicine, Dr. Porter Phillips and the members of the staff at the Bethlem Royal Hospital will give twice weekly a lecture-demonstration at 11 A.M. from Jan. 1lth to Feb. 5th, the fee for the course being $\mathfrak{f l} 1 \mathrm{~s}$.

From Jan. 10th to 22nd the North East London Post-Graduate College, Prince of Wales's General Hospital, Tottenham, N., will hold an intensive course in medicine, surgery, and the specialities. The fee for the course is five guineas, or three guineas for either week. Each day from 10.30 A.M. to 12.45 P.M. there will be practical demonstrations chiefly on clinical and laboratory methods. In the afternoon the general work of the hospitals will be in progress from 2.30 onwards till 6.30 , or later. In addition, there will be set demonstrations from 2 to 2.45 P.M. and at 4.30 P.M. each day a formal lecture on treatment or clinical subject not requiring the presence of patient. On the two Saturdays visits will be made to the N.E. Fever Hospital and the Colney Hatch Mental Hospital respectively.

Copies of all syllabuses will be forwarded on application to the Fellowship of Medicine, 1, Wimpolestreet, W. 1.

We are asked to announce that the complete list of Special Courses for 1927, arranged by the Fellowship of Medicine, is now ready. Also that it is hoped to begin a further series of lectures on Emergencies in Medicine and Surgery about the middle of January.

We thank "Post-Graduate" for his letter (p. 48), and for the suggestion it contains, and express the hope that each of the Deans or Secretaries of bodies engaged in post-graduate medical teaching outside London will send an advertisement of particulars of their forthcoming work as soon after the beginning of the month as possible, so that it may be in time for the next issue of the JournaL. 